considerable variation in individual levels within the groups, and the observed differences in the mean values are not statistically significant. The results of the present study do not suggest any consistent effect of T.D.I. Imferon therapy on vitamin $\mathrm{B}_{12}$ nutrition.

Though most of the subjects in the present study showed evidence of folate deficiency, no major reaction to T.D.I. Imferon therapy was encountered in a total of 81 infusions. This finding does not substantiate the suggestion that major reactions may be related to folate deficiency (Lane and Scott, 1965). Thrombophlebitis at the site of infusion occurred in five patients; it was not related to the use of $5 \%$ dextrose water as diluent for the Imferon, as only normal saline was used. The slow rate of infusion may possibly have been a factor in producing thrombophlebitis.

\section{Summary}

Iron-dextran by the total dose infusion technique was administered to 81 postpartum anaemic subjects with diminished marrow iron stores. Tests of iron, folate, and vitamin $B_{12}$ nutrition were carried out before therapy and repeated six weeks later.

Iron-dextran therapy was regarded as satisfactory in that anaemia was corrected and tests of iron nutrition returned to normal. In untreated control subjects anaemia was often spontaneously corrected, but this was accompanied by deterioration in iron nutrition.
Iron-dextran therapy retarded the improvement in tests of folate nutrition after confinement which occurred in untreated subjects. This substantiates the recommendation that folic acid be administered routinely to patients receiving Imferon therapy for anaemia associated with pregnancy.

No consistent effect of iron-dextran therapy on vitamin $B_{12}$ nutrition could be shown.

We wish to thank the Director, South African Institute for Medical Research, and the Superintendent, Baragwanath Hospital, Johannesburg, for facilities to carry out this study ; Dr. D. Lavery and Dr. R. Cassel for their help; Mrs. J. Oshry and Mrs. G. Bird for technical assistance; Sister $M$. Johnstone and the nursing staff at Baragwanath Hospital for their enthusiastic co-operation; and Fisons Chemicals (S.A.) (Pty.) Limited for supplies of Imferon. This study was supported in part by a research grant from the World Health Organization.

\section{REFERENCES}

Basu, S. K. (1965), 7. Obstet. Gynaec. Brit. Cwlth, 72, 253.

Basu, S. (1965). Brit. med. 7., 2, 1030.

Bonnar, J. (1965). Brit. med. f., 2, 1030. Biochem. 7., 59, 599.

Bothwell, T. H., and Mallett, B. (1955). Biochem. F., 59, 599.

Brandt, V., and Metz, J. (1961). S. Afr. 7. med. Sci., 26, 1. Charlton, R. W., Hardie, N., and Bothwell, T. H. (1965). Ibid., 30, 71.
Clay, B., Rosenberg, B., Sampson, N., and Samuels, S. I. (1965). Brit. med. F., 1, 29.

Combrink, P. B., Turchetti, L. C., Pannell, P., and Metz., J. (1966). S. Afr. med. F., 40, 234 .

Goldthorp, W. O., Spencer, D., and Dawson, D. W. (1965). Brit. med.

F., 1, 316.

Lane, R. S., and Scott, J. M. (1965). Brit. med. F., 1, 449.

Scott, J. M. (1963). Ibid., 2, 354.

Scott, J. M. (1963). Ibid., 2, 354.

Waters, A. H., and Mollin, D. L. (1961). F. clin. Path., 14, 335.

\title{
Influenza in the West of Scotland, 1966
}

\author{
J. C. TAYLOR,* M.R.C.P.glASG. ; CONSTANCE A. C. ROSS, † M.D., M.C.PATH. ; E. J. STOTT,† B.A.
}

Brit. med. F., 1967, 3, 406-408

The west of Scotland experienced concurrent epidemics of influenza type $A$ and type $B$ in the first quarter of 1966 . The present study describes virological and clinical findings in 119 cases diagnosed as influenza by the Regional Virus Laboratory, Ruchill Hospital. Four cases of encephalitis associated with one particular age group are also reported.

\section{Materials and Methods}

During the epidemics tests for influenza-A and for influenza$B$ infections were carried out on routine specimens received by the laboratory from patients either in hospital or at home. The patients investigated comprised not only those with influenzal symptoms but also those with infections of the upper and lower respiratory tracts or other pyrexial illnesses for which no other cause could be found. From most of the children only specimens for virus isolation were obtained because of the difficulty of obtaining sera. In contrast, from most of the adults sera only were collected because of limited laboratory resources for isolation of respiratory viruses.

Virus Isolation.-Specimens for virus isolation comprised swabs of throat or throat and nose. Each swab (cotton-wool on wooden shaft) at collection was broken into $2 \mathrm{ml}$. of transport medium (Grist et al., 1966). Of each extract $0.2 \mathrm{ml}$. was inoculated into one tube of secondary rhesus monkey kidney tissue culture, which was examined and maintained as described by Grist et al. (1966). Growth of either influenza-A (three strains) or influenza-B (23 strains) produced haemadsorp- tion and generally also cytopathogenic effect in three to seven days. The type of influenza was determined by complementfixation tests against both influenza- $A$ and influenza-B human convalescent sera. Influenza complement-fixing antigen was usually detected at the fifth to eighth day in the primary culture ; the remaining strains all fixed complement in the first passage, antigen titres ranging from 2 to 32 for the type $B$ strains and being 32 for all three type A strains. Titres of influenza-B haemagglutinin varied from $<4$ to 128 in the primary culture and from 8 to 256 in the first pass; titres of influenza- $A$ haemagglutinin were lower, being $<4$ in the primary culture and not above 8 after two passes. Representative type $A$ and type $B$ strains from children and adults were sent to Dr. H. G. Pereira, W.H.O. Influenza Centre, London, who reported that they were antigenically similar to recently isolated type A and B strains.

Serology.-Paired sera were examined for complementfixing antibodies against influenza- $A$ and influenza-B soluble antigens and against other relevant viral antigens as described by Grist et al. (1966). As the optimal concentrations of both influenza antigens were generally twofold to eightfold greater for young children than for older children or adults, two doses of each antigen were used: the higher concentration for testing sera from children under 6 years of age, and a four times lower

* University Department of Infectious Diseases, Ruchill Hospital, Glasgow N.W.

† Regional Virus Laboratory, Ruchill Hospital, Glasgow N.W. Salisbury, Wilts. 
concentration for sera from older children and adults. All titres in this paper are expressed as reciprocals.

\section{Virological Findings}

The criteria accepted as evidence of infection with influenzaA or influenza-B were virus isolation and/or positive serological findings comprising a fourfold or greater rise in titre, a high but not rising titre $(>256)$, or a fourfold or greater fall in titre.

Infection with influenza type A or type B was detected in 119 cases-61 due to type $A$ and 58 to type $B$ (Table I). A surprising finding was the complete absence of type A infections in the children aged 6 to 15 years, contrasting with the large number of type $B$ infections. This suggested that children aged 6 to 15 had a high level of immunity against type $A_{2}$, the current infecting type A strain in Britain since 1957, but were susceptible to type $B$ infection. In patients under 6 and over 15 years type $\mathrm{A}$ was diagnosed more frequently than type $\mathrm{B}$ infection.

TaBLE I.-Number of Cases with Influenza in Relation to Age

\begin{tabular}{|c|c|c|c|c|c|c|c|}
\hline \multirow{2}{*}{ Influenza } & \multicolumn{6}{|c|}{ Age Group (Years) } & \multirow{2}{*}{$\begin{array}{l}\text { Total } \\
\text { Cases }\end{array}$} \\
\hline & $0-5$ & $6-10$ & $11-15$ & $16-20$ & $21-50$ & $50+$ & \\
\hline $\begin{array}{c}\text { Type A } \\
\text {, B }\end{array}$ & $\begin{array}{l}9 \\
7\end{array}$ & $\begin{array}{r}0 \\
18\end{array}$ & $\begin{array}{l}0 \\
9\end{array}$ & $\begin{array}{l}7 \\
2\end{array}$ & $\begin{array}{l}12 \\
10\end{array}$ & $\begin{array}{l}33 \\
12\end{array}$ & $\begin{array}{l}61 \\
58\end{array}$ \\
\hline Total cases .. & 16 & 18 & 9 & 9 & 22 & 45 & 119 \\
\hline
\end{tabular}

Comparison of Virus Isolation and Serology.-Specimens for both virus isolation and serology were received from only 18 of the 119 influenza patients. Though the numbers are small the results shown in Table II suggest that at ages of over 5 years serological diagnosis by complement fixation was more reliable than virus isolation. In contrast, of the three children under 3 years of age from whom virus was isolated, only one showed a complement-fixing antibody response.

TABLE II.-Comparison of Virus Isolation and Serology

\begin{tabular}{|c|c|c|c|c|}
\hline \multirow{2}{*}{ Age in Years } & \multirow{2}{*}{ No. of Cases } & \multicolumn{3}{|c|}{ Virology } \\
\hline & & $\mathrm{VI}+. \mathrm{S}+$ & $\mathrm{VI}+. \mathrm{S}-$ & $\mathrm{S}+. \mathrm{VI}-$ \\
\hline $\begin{array}{l}\text { Under } 3 \\
6-15 \text { Over } 15 \\
\text { Ovi }\end{array}$ & $\begin{array}{l}3(1) \\
6 \\
9(4)\end{array}$ & $\begin{array}{l}1(1) \\
3(1) \\
7(2)\end{array}$ & $\begin{array}{l}2 \\
0 \\
0\end{array}$ & $\begin{array}{l}0 \\
3 \\
2(2)\end{array}$ \\
\hline Total & $18(5)$ & $11(3)$ & 2 & $5(2)$ \\
\hline
\end{tabular}

Figures in parentheses indicate number of type A cases; others were type $B$. VI $+=$ Influenza virus isolation positive. VI $-=$ Influenza virus isolation nega ive $\mathbf{S}+=$ Influenza serology position. $\mathbf{S}-=$ Influenza serology negative.

Complement-fixing Antibody Response and Age.-Previous workers have shown that the complement-fixing antibody response to soluble antigen is poor in young children with influenza (Grist, 1957 ; Henle and Lief, 1960). This was confirmed in the present study. Thus, of 60 patients in whom a rise in antibody titre and/or positive virus isolation had been demonstrated, titres greater than 32 were obtained in 36 out of 41 over 15 years of age, in three out of five aged 6 to 15 years, but in none of 14 children under 6 years old.

\section{Clinical Features}

The presenting clinical diagnoses in the 88 patients admitted to hospitals are listed in Table III in order of frequency. These patients probably represent the most severe clinical illnesses and complications in the various age groups. Pneumonia was found in all four age groups but was less common in children under 6 years than in the other groups. Influenza was not diagnosed in any of the children under 6 years. The diagnoses which were particularly associated with specific age groups were: croup in the children under 6 years (four of the five cases being under 3 years), encephalitis in those aged 6 to 15 (all four cases being from 6 to 10 years), and acute exacerbations of chronic bronchitis in those over 50 .

TABLE III.-Presenting Clinical Diagnosis in 88 Hospital Patients with Influenza

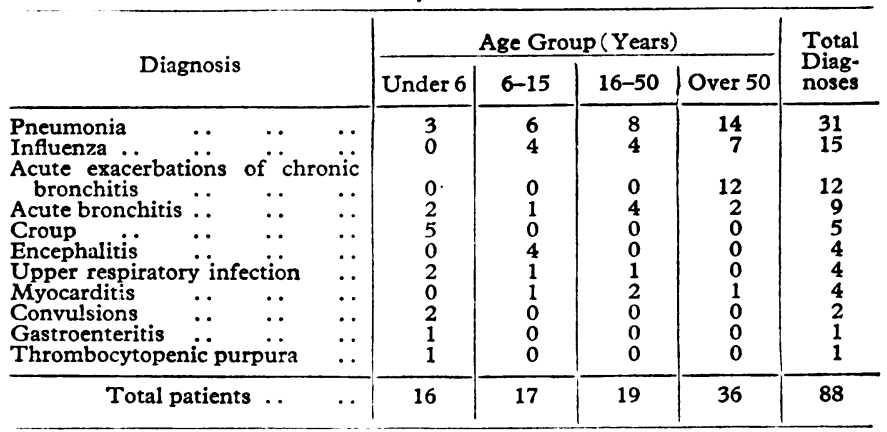

\section{Encephalitis}

As the children with encephalitis showed severe neurological involvement their case histories are given below.

Case 1.-A girl aged 6 years had a fatal illness. On 21 February 1966 she developed sore throat, fever, and cough. Three days later her behaviour became abnormal. On admission to another hospital she was semiconscious, reflexes were brisk, and the plantar reflexes were extensor. Over the next two days she became unconscious. On admission to Ruchill her temperature was $101.6^{\circ}$ F. $\left(38.7^{\circ} \mathrm{C}\right.$.). The tendon reflexes were now absent and the plantar reflexes were extensor. The pupils did not react to light. She was cyanosed and had bulbar paralysis. She died on 28 February, the eighth day of illness. At necropsy the striking feature was marked swelling of the brain due to oedema, but there was no coning. Microscopical examination showed no demyelinization.

Case 2.-A girl of 6 years developed coryza and cough on 19 January 1966. Four days later she was found unconscious. On admission to Ruchill on the sixth day of illness she was in coma. There was nuchal rigidity; the tendon reflexes were present, the plantar reflexes were flexor, and the pupils reacted normally. There were occasionai purposeless movements of the arms and trunk but no true convulsions. The temperature was $100.6^{\circ} \mathrm{F}$. $\left(38.1^{\circ} \mathrm{C}\right.$.). Improvement was apparent four days after onset of coma. Recovery was complete when discharged on 12 February.

Case 3.-A girl of 8 years developed coryza, cough, and vomiting on 25 January 1966 . She improved, but after seven days vomiting and cough returned and she talked nonsense. On the ninth day she became unresponsive to stimuli. There were no convulsions. On admission to Ruchill on 4 February her temperature was $101^{\circ} \mathrm{F}$. $\left(38.3^{\circ}\right.$ C.). Consciousness varied from stupor to coma; reflexes were depressed, muscle tone was low, but the plantars were flexor. The pupils reacted normally and meningism was absent. There were occasional purposeless movements of the upper limbs. Recovery took place very slowly: she began to respond to orders six days from loss of consciousness, but it was another 10 days before her mentality appeared normal. Ultimately recovery was complete.

Case 4.-A boy of 9 years was admitted to hospital on 15 January 1966 after five days' coryza and cough and one day's twitching and incontinence of urine. On admission his temperature was $100.4^{\circ} \mathrm{F}$. $\left(38^{\circ} \mathrm{C}\right.$.). The tonsils and pharynx were inflamed and the lips were blistered. He had several convulsions in which his gaze deviated to the right, but the convulsive movements were mainly of the left side of his body. Next day he was found to have a left monoparesis of the arm, his left plantar reflex was extensor, and he was in coma. He was transferred to a neurological unit for further investigations. Convulsions ceased 48 hours after onset of nervous symptoms. Right carotid angiography was negative and his left monoparesis was improving when he was returned to Ruchill on the 12th day of illness. Recovery was complete when discharged on 28 March.

Laboratory Findings. - The relevant laboratory findings in the four cases of encephalitis are shown in Table IV. Cerebrospinal fluid showed an increase in cells and/or protein in Case 2 only; 
this was the only patient with clinical evidence of meningeal irritation. Evidence of active or recent infection with influenza-B virus was obtained in all cases. The isolation of influenza-B from Cases 1 and 4 and absence of detectable antibody in their "acute" sera indicated that in these two cases the onset of encephalitis occurred early in the illness. However, it was of interest that Case 1 also showed evidence of recent infection with respiratory syncytial virus (high but not rising titres) and Case 4 had an active concurrent infection with herpes simplex (virus isolation and a rising titre). In contrast, failure to isolate influenza virus from Cases 2 and 3 along with high but not rising titres to this virus indicated onset of encephalitis late in the illness.

TABLE IV.-Laboratory Findings in Encephalitis Cases

\begin{tabular}{|c|c|c|c|c|c|c|c|}
\hline \multirow{3}{*}{ Case } & \multirow{3}{*}{$\mid \begin{array}{c}\text { Age } \\
\text { in } \\
\text { Years }\end{array}$} & \multirow{2}{*}{\multicolumn{3}{|c|}{$\begin{array}{l}\text { Cerebrospinal } \\
\text { Fluid } \\
\text { (per ml.) }\end{array}$}} & \multirow{3}{*}{$\begin{array}{l}\text { Virus } \\
\text { Isolations } \\
\text { (Throat } \\
\text { and Nose } \\
\text { Swabs) }\end{array}$} & \multicolumn{2}{|c|}{ Serum } \\
\hline & & & & & & \multirow{2}{*}{$\begin{array}{c}\text { Day of } \\
\text { Illness } \\
\text { Acute/conv. }\end{array}$} & \multirow{2}{*}{$\begin{array}{l}\text { Influenza-B } \\
\text { C.F. Titres } \\
\text { Acute/conv. }\end{array}$} \\
\hline & & Cells & Protein & Sugar & & & \\
\hline $\begin{array}{l}1 \\
2 \\
3 \\
4\end{array}$ & $\begin{array}{l}6 \\
6 \\
8 \\
9\end{array}$ & $\begin{array}{r}5 \\
30 \\
1 \\
1\end{array}$ & $\begin{array}{l}15 \\
60 \\
20 \\
20\end{array}$ & $\begin{array}{l}65 \\
68 \\
71 \\
79\end{array}$ & $\begin{array}{l}\text { Influenza-B } \\
\text { Negative } \\
\text { Negative } \\
\text { Influenza-B. } \\
\text { Herpes } \\
\text { simplex }\end{array}$ & $\begin{array}{c}7 / N D \\
6 / 21 \\
11 / 22 \\
5 / 17\end{array}$ & $\begin{array}{l}*<8 / N D \\
256 / 256 \\
512 / 128 \\
<8 / 16 \dagger\end{array}$ \\
\hline
\end{tabular}

Also high titre (512) for respiratory syncytial virus. † Rising titre for herpes simplex

\section{Discussion}

Previous studies, such as those described in the Report of the M.R.C. Working Party on Acute Respiratory Virus Infections (1965), have shown that the clinical picture of influenza and its complications may be very variable, being more frequently atypical at the extremes of life. In young children influenza is generally a mild illness and respiratory complications are rare. The present study has confirmed the variability of the clinical picture, particularly as seen in young children. Though croup was the commonest presenting diagnosis in those under 6 years of age in hospital, none required tracheostomy. In the hospital patients over 50 years old respiratory complications were frequent, the majority presenting with pneumonia or an acute exacerbation of chronic bronchitis; these are well-recognized complications of influenza in older patients (Stuart-Harris, 1966).

Development of encephalitis early and late in the influenzal illness has been described by Hoult and Flewett (1960), who suggested that in the early type of encephalitis in which histological lesions were minimal the damage might be caused by toxin or by actual virus multiplication, and that the late type showing perivascular demyelination might be produced by antibrain antibodies. In the four cases described in the present study virological findings suggested that encephalitis developed early in the influenzal illness in two and late in the other two. Of the two early cases the patient who died (Case 1) showed serological evidence of recent infection with respiratory syncytial virus; this may have accounted for the severity of the ensuing influenzal infection. The other patient (Case 4) had a concurrent infection with herpes simplex, so it is uncertain whether influenza-B or herpes simplex or a synergic effect of both viruses caused the encephalitis.

All four patients with encephalitis in the present series were aged 6 to 10 years; the absence of this complication in the younger and older age groups is surprising. A possible explana- tion is that the patients aged 6 to 10 years had the greatest number of type B infections, many of which were probably primary. However, the absence of encephalitis in those under 6 years, in whom there would be an even higher proportion of both type A and type B primary infections, suggests that some other factor relevant to age was related to the onset of encephalitis. In this connexion the poor antibody response of young children to influenza might be relevant, as development of the late type of encephalitis might require both a primary infection and a good antibody response. The poor antibody response of young children might protect them against the type of encephalitis which Webb and Smith (1966) have suggested may be associated with an antigen-antibody reaction. If this type of reaction is concerned in the late type of influenza encephalitis then the age incidence of this complication might depend on the peak age incidence (excluding very young children) of primary infection with influenza; this would vary from epidemic to epidemic, depending on the community's previous experience of the infecting influenza strain or antigenically related strains. To establish a correlation between encephalitis and primary infection detailed serological surveys of influenza antibodies in different age groups of the community would be required. As such surveys had not been done in this area before the present epidemics, further investigations along these lines are indicated.

\section{Summary}

During the first quarter of 1966 there were concurrent epidemics of influenza type A and type B in the Glasgow area. Virological diagnosis of active infection with type $A$ was made in 61 patients and of type $B$ in 58. Type $A$ infections were more frequent than type $B$ in patients under 6 years and in those over 15 years. In children aged 6 to 15 years no type $A$ but a large number of type $B$ infections were detected. This suggested that children aged 6 to 15 years had high immunity against type $A_{2}$, the current infecting type $A$ strain in Britain since 1957 , but were susceptible to type B infections.

In 88 patients admitted to hospital the clinical diagnoses particularly associated with specific age groups were: croup in children under 6 years old, encephalitis in those aged 6 to 10, and acute exacerbations of chronic bronchitis in patients over 50. The four encephalitis cases are described and possible reasons for development of this complication are discussed.

We are grateful to the many doctors in hospital, public health, and general practice (particularly Drs. W. Blair and A. Clarke) who sent us specimens; and to Professor T. Anderson and Dr. I. W. Pinkerton for permission to publish details of the encephalitis cases. We thank Dr. H. G. Pereira, W.H.O. Influenza Centre, Mill Hill, London, for antigenic analysis of influenza strains, Dr. J. F. Boyd for necropsy findings, and Mr. S. McMichael, A.I.M.L.T., and Miss M. Walker for valuable technical assistance.

\section{REFERENCES}

Grist, N. R. (1957). Scot. med. f., 2, 249.

Ross, C. A. C Bell, E. J., and Stott, E J. (1966) Diagnostic Methods in Clinical Virology. Oxford.

Henle, W., and Lief, F. S. (1960). F. Immunol., 84, 491

Hoult, G., and Flewett, T. H. (1960). Brit. med. f., 1, 1847.

Medical Research Council (1965). Ibid., 2, 319.

Stuart-Harris, C. H. (1966). Ibid., 1, 149.

Stuart-Harris, C. H. (1966). Ibid., 2, 1179. 